\title{
Effectof Nebulised 3\% Hypertonic Saline in Children Hospitalized with Typical Viral Bronchiolitis.
}

\author{
Dr. G. Arun Prakash ${ }^{1}$, Dr.D.Vignadharshan ${ }^{2}$, \\ Dr.Pagadpally Srinivas ${ }^{3}$ \\ Assistant Professor ${ }^{1}$, Assistant Professor ${ }^{2}$, Associate Professor ${ }^{3}$, \\ Dept. Of Pediatrics, Vinayaka Missions Medical College, Karaikal
}

\begin{abstract}
:
Objective:To study the effect of addition of frequently nebulised $3 \%$ hypertonic saline to the standard therapy of infants hospitalized with viral bronchiolitis.

Design: Prospective, randomized control study

Setting:A tertiary care teaching hospital in Kanchipuram

Participants: 100 Children aged 2 months to 18 months who are admitted to the hospital for the treatment of moderately severe viral bronchiolitis

Methods:3 ml of nebulised study solution containing 3\% hypertonic saline is given along with standard therapy of Nebulised salbutamol with supportive therapy like oxygen,i.v. fluids \&paracetamol for 50 randomly selected children

Outcome measured:Length of stay in hospital

Results :Among 100 children with bronchiolitis, Mean length of hospital stay of the 50 children in study group as 71.8 hours while that of the 50 children in control group was 111.12 hours $(p=0.00)$.

Conclusion:The use of nebulised 3\% hypertonic saline in treating viral bronchiolitis in moderately ill hospitalized children upto age of 18 months reduces length of stay in hospital.

Keywords:Bronchiolitis, Hypertonic Saline (HT), standard therapy Salbutamol, Retractions, Respiratory Distress Assessment Instrument (RDAI), SaO2,Oxygen, standard therapy $(S T)$, Length of stay.
\end{abstract}

\section{Introduction}

Acute Bronchiolitis is predominantly a viral disease of the smaller airways characterized by bronchiolar obstruction with edema, mucus and cellular debris.

The AAP guidelines defined Bronchiolitis as "a constellation of clinical symptoms and signs including a viral upper respiratory prodrome followed by increased respiratory effort and wheezing in children less than 2 years of age."

Respiratory syncytial virus (RSV) is the most commonly isolated agent in $75 \%$ of children less than 2 years of age hospitalized for Bronchiolitis. ${ }_{1,2,3,4,5,6,7}$.

According to the World Health Organization bulletin, an estimated 150 million new cases occur annually; 11-20 million (7-13\%) of these cases are severe enough to require hospital admission. Worldwide, majority of all cases occur in developing countries. ${ }^{8,9}$

Assessment of severity of bronchiolitis based on guidelines from New zealand and Scotland is given as ${ }^{10}$

\begin{tabular}{|l|l|l|l|}
\hline & Mild & Moderate & Severe \\
\hline Feeding & Normal & $\begin{array}{l}\text { Less than usual } \\
>\text { half the normal }\end{array}$ & $\begin{array}{l}\text { Not interested } \\
<\text { half the normal }\end{array}$ \\
\hline Respiratory rate & $\begin{array}{l}<2 \text { months }->60 / \mathrm{min} \\
>2 \text { months }->50 / \mathrm{min}\end{array}$ & $>60 / \mathrm{min}$ & $>70 / \mathrm{min}$ \\
\hline Chest wall retractions & Mild & Moderate & Severe \\
\hline Nasal flare or Grunting & Absent & Absent & Present \\
\hline Sao2 & $>92 \%$ & $88-92 \%$ & $<88 \%$ \\
\hline General behaviour & Normal & Irritable & Lethargic \\
\hline
\end{tabular}

Despite high prevalence and morbidity of Bronchiolitis, therapy remains controversial. Nevertheless the use of nebulised Bronchodilators continues to be common, despite extensive evidence supported that benefits are limited and short term. 
The primary treatment therefore, remains supportive, with administration of fluids and supplemental oxygen, observation and mechanical ventillatory support as needed. ${ }_{12}$,

Several reports over the last decade have demonstrated that inhalation of nebulised $6 \%$ to $10 \%$ hypertonic saline improves both immediate and long term clearance of small airways in patients with cystic fibrosis. 13,14

It is thought to facilitate removal of inspissated mucus through osmotic hydration, disruption of mucus strand cross linking, and reduction of mucosal edema. Similar mechanism can help in the treatment of Bronchiolitis. ${ }^{15,16}$

This study was done to ascertain the usefulness of addition of $3 \%$ saline in the treatment of Bronchiolitis to alleviate the symptoms and reduce the length of hospital stay in children aged 2 months to 18 months.

\section{Study design and Participants:}

\section{Methods}

A Prospective, randomized control study was conducted at a tertiary care teaching hospital in Kanchipuram between January 2013 to september 2014 for a period of 18 months.

\section{Inclusion criteria:}

Children from 2 months to 18 months who were admitted in the hospital for the treatment of moderately severe viral Bronchiolitis were eligible for the study.

Selection of patients was made according to diagnostic criteria for acute Bronchiolitis:

a. History of a preceding viral upper respiratory infection,

b. The presence of wheezing and /or crackles on chest auscultation

\section{Plus either}

An oxygen saturation $(\mathrm{SaO} 2)$ of $<94 \%$ in room air OrSignificant respiratory distress as measured by a Respiratory Distress Assessment Instrument (RDAI) ${ }^{17}$

\section{Exclusion criteria:}

Children withMild or severe cases of bronchiolitis, Chronic cardiopulmonary disease and with history of use of nebulised hypertonic saline within the previous 12 hours were excluded from the study.

Children who fulfilled the eligibility criteria and whose parents provided written consent were randomized to receive or not to receive nebulised $3 \%$ hypertonic saline. The study was approved by the Ethical committee of the institution.

\section{Sample size:}

Total number of 100 children were included in the study. They were randomized into two groups i.e. study and control group each containing 50.

\section{Intervention:}

Baseline demographic data collected at study entry by taking interview of parents regarding complaints. Observation of findings and investigations were recorded.

Clinical history and examination were done as per the case proforma. Assessment of patients with RDAI score ${ }^{17}$ and Sao2 readings by pulse oximeter were done within 12 hrs of admission (study entry) and at least two times daily till patient attained protocol defined discharge criterion. In brief, 6 separate assessments of retractions and auscultatory findings were made and assigned a numerical score; the sum of these scores provided the RDAI score ranging 0 to 17 , with increasing score indicating increasing respiratory distress.

Oxygen saturation was measured using a pulse oximeter with the infant in a quiet state after breathing room air for at least 10 minutes.

Chest $x$ ray and total WBC \& differential counts were done as per Physicians guidelines to support the diagnosis of viral Bronchiolitis. 
Patients were randomized to receive treatment either with:

$3 \mathrm{ml}$ of nebulised study solution containing $3 \%$ hypertonic saline along with standard therapy. i.e. HT + ST( Study group) Or Only standard therapy. i.e. ST( Control group)

Standard therapy consisted of only nebulised salbutamol along with supportive therapy i.e. oxygen, intravenous fluids \&paracetamol (in case of fever)

Nebulised Salbutamol was given as per the clinical severity or at least $6^{\text {th }}$ hourly. The study solution was administered every $8^{\text {th }}$ hourly daily until discharge. All inhaled therapies were delivered to an infant from a standard oxygen-derived hospital nebulizer through a tight fitting facemask or hood whichever was better tolerated by patient.

Clinical response was determined by RDAI scores and $\mathrm{SaO} 2$ readings by the pulseoximeter at study entry and then at least two times daily until discharge. At the daily assessment, parents were interviewed to determine if any adverse events were present.

Respiratory Distress Assessment Instrument (RDAI) 17
\begin{tabular}{|l|l|l|l|l|l|l|}
\hline & & 1 & 2 & 3 & 4 & Max \\
\hline Wheezing & & & & & & \\
\hline Expiration & None & End & $1 / 2$ & $3 / 4$ & All & 4 \\
\hline Inspiration & None & Part & All & -- & -- & 2 \\
\hline Location & None & Segmental & Diffuse & -- & -- & 2 \\
\hline
\end{tabular}

\begin{tabular}{|l|l|l|l|l|l|l|}
\hline & 0 & 1 & 2 & 3 & 4 & Max \\
\hline Retractions & & & & & & \\
\hline Supraclavicular & None & Mild & Moderate & Marked & -- & 3 \\
\hline Intercostal & None & Mild & Moderate & Marked & -- & 3 \\
\hline Subcostal & None & Mild & Moderate & Marked & -- & 3 \\
\hline Total
\end{tabular}

\section{Study outcomes:}

Primary outcome measured was Length Of Stay in Hospital (LOS).LOS was defined as the time between study entry (within 12 hrs of admission to the hospital) and the time at which the patient reached the protocol defined discharge criterion of both an RDAI score $<4$ and Sao 2 of atleast $95 \%$ in room air for $4 \mathrm{hrs}$.

\section{Statistical analysis}

Data were recorded on a predesigned proforma. Comparative analysis of baseline parameters of the two groups was done using Chi Square test to examine association between categorical variables and group, and Independent sample't' tests and Levene's test for equality of variance to assess the association between numerical variables and group. All the statistical analysis was done by using SPSS 12.0 version.

\section{Results}

Of the 100 children enrolled, 64 (64\%) were in the age group of 6 months to 12 months and $63(63 \%)$ of them were males

Of the 50 children randomized for study group, $32(64 \%)$ had RDAI score of 8 to 10 with an average of 9.94 . The average saturation recoded in the study group children was 92.76 +-1.53 .

Among the 50 children in control group, 35(70\%) had RDAI score of 8 to 10 with an average of 9.92. The average saturation in control group was 92.16+-1.66.

The mean LOS in the study group was 71.80 hours whereas in control group it was 111.12 hours $(\mathrm{p}=0.00)$.

So there was on an average 39 and half hours reduction in length of stay in patients treated with $3 \%$ hypertonic saline in addition to standard therapy compared to those treated with standard therapy alone.

This shows that there is significant difference between the study and control group in the total length of hospitalization due to the addition of nebulised $3 \%$ hypertonic saline. 


\begin{tabular}{|l|l|l|l|}
\multicolumn{2}{|c}{ Baseline Profile of Patients Enolled In Study } \\
\hline & $\begin{array}{l}\text { Study group } \\
(\text { HS+ST) } \\
(\mathbf{n = 5 0})\end{array}$ & $\begin{array}{l}\text { Control group } \\
(\mathbf{S T}) \\
(\mathbf{n}=\mathbf{5 0})\end{array}$ & P value \\
\hline Age (months) & $6.96 \pm 2.77$ & $7 \pm 3.23$ & .131 \\
\hline Lessthan 6 months & 15 & 14 & .346 \\
\hline $\begin{array}{l}\text { Sex } \\
\text { Males }\end{array}$ & 32 & 31 & .721 \\
Females & 18 & 19 & .610 \\
\hline $\begin{array}{l}\text { Respiratory distress } \\
\text { Clinical score }\end{array}$ & $9.94 \pm 1.206$ & $9.92 \pm 1.30$ & 1.0 \\
\hline Sao2\% in room air & $92.76 \pm 1.53$ & $92.16 \pm 1.66$ & .241 \\
\hline
\end{tabular}

\section{Independent Samples Test}

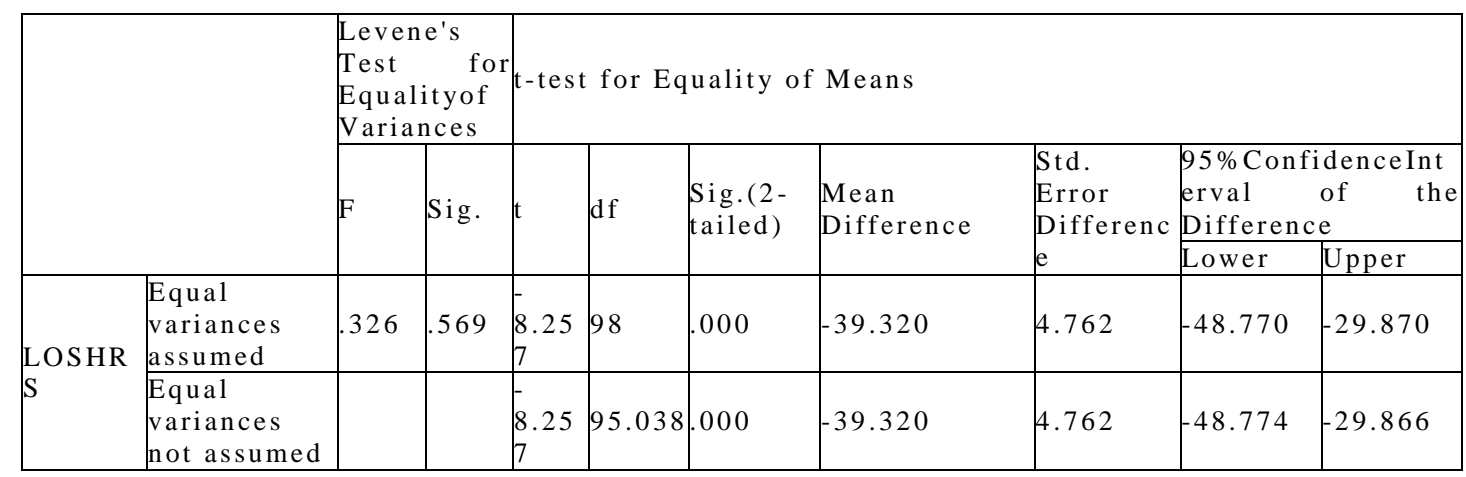

\section{Group Statistics}

\begin{tabular}{|l|l|l|l|l|l|}
\hline & STUDY & N & Mean & Std. Deviation & Std. Error Mean \\
\hline \multirow{2}{*}{ LOSHRS } & Study & 50 & 71.80 & 21.607 & 3.056 \\
\cline { 2 - 6 } & Control & 50 & 111.12 & 25.827 & 3.653 \\
\hline
\end{tabular}

\section{Discussion}

This study looked at the benefit of $3 \%$ hypertonic saline as an add on therapy to nebulised salbutamol along with supportive therapy in the management of viral bronchiolitis. The results of this study revealed that nebulised $3 \%$ hypertonic saline in the management of viral bronchiolitis in children upto 18 months of age is an effective adjuvant to the standard treatment.

Kuzik et al ${ }^{11}$ showed a clinically relevant reduction (approximately 1 day) in the length of hospitalization in children with acute viral bronchiolitis treated with nebulised $3 \%$ hypertonic saline.

Similarly, Mendelberg et $1^{18}$, demonstrated that nebulised $3 \%$ saline could produce a reduction of 0.8 days in the mean length of hospital stay. Results of our study were comparable to data from these studies.

. Use of salbutamol can be justified by the facts that, it has been widely used in more than $80 \%$ bronchiolitis patients ${ }^{19}$; with reduction in RDAI scores significantly more than placebo ${ }^{11,20}$; AAP guidelines support the usage of nebulised salbutamol in bronchiolitis

We monitored for adverse effects to $3 \%$ HS by interviewing parents at least two times daily. $3 \%$ hypertonic saline was well tolerated by infants in our study and there were no apparent adverse effects or worsening after treatment was noted.

\begin{tabular}{|l|l|l|l|}
\hline Study & Kuzik et. al ${ }^{11} \mathbf{2 0 0 7}$ & Mendelberg et.al ${ }^{17} \mathbf{2 0 0 3}$ & Our study \\
\hline $\begin{array}{l}\text { Number of cases in HS } \\
\text { group }(\mathrm{n})\end{array}$ & 47 & 30 & 50 \\
\hline $\begin{array}{l}\text { Mean age of patients in } \\
\text { months }\end{array}$ & 4.7 & 2.9 & 6.96 \\
\hline $\begin{array}{l}\text { Gender (male) } \\
\begin{array}{l}\text { Mean Length of stay in } \\
\text { hours (LOS) }\end{array}\end{array} \quad 62.4 \pm 45.6$ & $63 \%$ & $64 \%$ \\
\hline Reduction in LOS in hours & 21.6 & $67.2 \pm 31.2$ & $71.8 \pm 21.38$ \\
\hline Adverse effects & Nil & 19.2 & 39.32 \\
\hline
\end{tabular}


Use of $3 \%$ hypertonic saline can be safe, cost effective and has the potential of enormous economic benefit in developing countries like India with limited resources. Even half a day reduction in LOS as will substantially reduce hospital costs for bronchiolitis especially in public health care facilities.

There is need for large scale multicentric double blinded randomized control studies in order to delineate about 1) dose of $3 \%$ HS to be used; 2) adverse effects to be monitored and 3 ) usefulness in cases other than that caused by RSV.

\section{Bibliography}

[1]. Abreu e Silva FA, Brezinova V, Simpson H. Sleep apnea in acute bronchiolitis. Arch Dis Child. 1982; 57:467-472.

[2]. American Academy of Pediatrics Subcommittee on diagnosis and management of bronchiolitis Pediatrics 2006;118:1774-93.

[3]. Amirav I, Luder AS, Kruger N, et al. A double-blind, placebo-controlled, randomized trial of montelukast for acute bronchiolitis. Pediatrics. Dec 2008;122(6):e1249-55.

[4]. Antonow JA, Hansen K, McKinstry CA, Byington CL. Sepsis evaluations in hospitalized infants with bronchiolitis. Pediatr Infect Dis J. Mar 1998;17(3):231-6

[5]. Assouline G, LeibsonV,Danon A. Stimulation of prostaglandin output from rat stomach by hypertonic solution. European Journal of Pharmacology 1977;44:271-3.

[6]. AvigdorMandelberg,; Guy Tal,; Michaela Witzling,;Eli Someck,; SionHouri,; Ami Balin,; and Israel E. Priel,Nebulized 3\% Hypertonic Saline Solution Treatment in Hospitalized Infants With Viral Bronchiolitis, CHEST 2003; 123:481-487

[7]. Beasley JM, Jones SEF. Continuous positive airway pressure in bronchiolitis. Br Med J. 1981; 283:1506-1508.

[8]. Daugberg P, Brenoe E, Forchhammer H, et al. A comparison between nebulized terbutaline, nebulized corticosteroid and systemic corticosteroid for acute wheezing in children up to 18 months of age. ActaPaediatr. 1993; 82:547-551.

[9]. Daviskas E, Anderson SD, Gonda I, Eberl S, et al. Inhalation of hypertonic saline aerosol enhances mucociliary clearance in asthmatic and healthy subjects. European Respiratory Journal 1996;9(4):725-32

[10]. Knut oymar, HavardoveSkjerven and IngvildBruunMikalsen et al Acute bronchiolitis in infants, a review, Scandinavian Journal of Trauma Resuscitation and Emergency Medicine 2014 /10.1186/1757-7241-22-23

[11]. John F. Price Viral Bronchiolitis In Infancy Jr Lung

[12]. Kattan M, Keens TG, Lapierre JG, et al. Pulmonary function abnormalities in symptom-free children after bronchiolitis. Pediatrics. 1977; 59:683-688.

[13]. Stein RT, Sherrill D, Morgan WJ, Holberg CJ, Halonen M, Taussig LM, et al Respiratory syncytial virus in early life and risk of wheeze and allergy by age 13 years. Lancet 1999;354:541-5.

[14]. Stretton M, Ajizian SJ, Mitchell I, Newth CJL. Intensive care course and outcome of patients infected with respiratory syncytial virus. PediatrPulmonol. 1992; 13:143-150.

[15]. Susanne M. Bu“ low, ; Marta Nir,; E. Levin, BirgitteFriis ; Lise L. Thomsen: Prednisolone Treatment of Respiratory Syncytial Virus Infection: A Randomized Controlled Trial of 147 Infants

[16]. Tal A, Bavilski C, Yohai D, et al. Dexamethasone and salbutamol in the treatment of acute wheezing in infants. Pediatrics. 1983; 71:13-18.

[17]. PREVENT study group. Reduction of respiratory syncytial virus hospitalization among premature infants and infants with bronchopulmonary dysplasia using respiratory syncytial virus immune globulin prophylaxis. Pediatr. 1997; 99:93-99.

[18]. Wandstrat TL. Respiratory syncytial virus immune globulin intravenous. Ann Pharmacother. 1997; $31: 83-88$

[19]. Guideline American Academy of Pediatrics Subcommittee on Diagnosis and Management of Bronchiolitis. Diagnosis and management of bronchiolitis. Pediatrics. Oct 2006;118(4):1774-9

[20]. Kuppermann N, Bank DE, Walton EA, Senac MO Jr, McCaslin I. Risks for bacteremia and urinary tract infections in young febrile children with bronchiolitis. Arch PediatrAdolesc Med. Dec 1997;151(12):1207-14. 